\title{
The 2D Structure of the T. brucei Preedited RPS12 mRNA Is Not Affected by Macromolecular Crowding
}

\author{
W.-Matthias Leeder, Stephan Voskuhl, and H. Ulrich Göringer \\ Department of Molecular Genetics, Darmstadt University of Technology, Darmstadt, Germany \\ Correspondence should be addressed to H. Ulrich Göringer; goringer@bio.tu-darmstadt.de
}

Received 3 February 2017; Accepted 4 April 2017; Published 18 June 2017

Academic Editor: Luis A. Marky

Copyright (C) 2017 W.-Matthias Leeder et al. This is an open access article distributed under the Creative Commons Attribution License, which permits unrestricted use, distribution, and reproduction in any medium, provided the original work is properly cited.

\begin{abstract}
Mitochondrial transcript maturation in African trypanosomes requires RNA editing to convert sequence-deficient pre-mRNAs into translatable mRNAs. The different pre-mRNAs have been shown to adopt highly stable 2D folds; however, it is not known whether these structures resemble the in vivo folds given the extreme "crowding" conditions within the mitochondrion. Here, we analyze the effects of macromolecular crowding on the structure of the mitochondrial RPS12 pre-mRNA. We use high molecular mass polyethylene glycol as a macromolecular cosolute and monitor the structure of the RNA globally and with nucleotide resolution. We demonstrate that crowding has no impact on the 2D fold and we conclude that the MFE structure in dilute solvent conditions represents a good proxy for the folding of the pre-mRNA in its mitochondrial solvent context.
\end{abstract}

\section{Introduction}

The folding of RNA molecules into compact, native structures or ensembles of structures is dictated by a set of firstprinciple physicochemical forces [1]. One of which is charge compensation to overcome the electrostatic repulsion of the negatively charged phosphodiester backbone [2-4]. Monoand divalent metal ions at low to high millimolar concentrations contribute to this task [5] and the effects of metal ionradius and charge density have been studied in detail [6-8]. Next to metal ions, metabolites, polyamines, and osmolytes have been shown to modulate RNA structure [9-13] as well as high concentrations of macromolecules, which can occupy up to $30 \%$ of the total volume of a cellular compartment. This generates so-called "crowded" solvent conditions [1416], which in general stabilize RNA 2D and 3D structures through the excluded volume effect and entropy perturbation of the folding landscape $[5,17,18]$.

RNA editing describes a posttranscriptional modification reaction of mitochondrial pre-mRNAs that is characterized by the site-specific insertion and deletion of exclusively $\mathrm{U}$ nucleotides (for a review, see [19]). The reaction takes place within the single mitochondrion of trypanosomes, which represents the most crowded intracellular environment of eukaryotic cells. Intramitochondrial macromolecular concentrations reach up to $560 \mathrm{~g} / \mathrm{L}$ [20, 21]. Editing is catalyzed by a macromolecular protein complex, the $20 \mathrm{~S}$ editosome [19], which interacts with 18 mitochondrial pre-mRNAs as substrates in the processing reaction. The different transcripts encode subunits of the mitochondrial electron transport and oxidative phosphorylation chains and have been characterized by several unusual features: first, the majority of pre-mRNAs lack substantial sequence information (on average $45 \%$ ); hence they require RNA editing to be converted into translatable mRNAs. Second, the different premRNAs are typified by an extraordinarily high G-content (34\%), which in two-thirds of the cases are clustered in tracts of G-nucleotides $(2 \leq \mathrm{G} \leq 8)$. Third, in vitro chemical probing studies revealed that the different pre-mRNAs adopt extraordinarily stable 2D- structures approaching the stability of structural RNAs [22, 23]. Next to canonical basepairing, they contain pseudoknots and in many cases multiple G-quadruplex (GQ) folds. However, it is not clear whether these $2 \mathrm{D}$ structures resemble the in vivo folds given the extreme crowding conditions in the trypanosome mitochondrion. This is especially important since RNA editing in vitro has been shown to be sensitive to crowded solvent properties [24]. 
Here, we analyze the effect(s) of macromolecular crowding on the structure of the mitochondrial RPS12 pre-mRNA as an archetypical example of a mitochondrial transcript in African trypanosomes. We use high molecular mass polyethylene glycol (PEG) as a neutral macromolecular cosolute to mimic intramitochondrial solvent conditions and we monitor the structure of the RPS12 transcript by temperaturedependent UV-spectroscopy and by selective $2^{\prime}$-hydroxyl acylation analyzed by primer extension (SHAPE).

\section{Materials and Methods}

2.1. DNA-Cloning and RNA Synthesis. The mitochondrial gene encoding ribosomal protein S12 (RPS12) was PCRamplified from T. brucei Lister 427 genomic DNA (see [25]) using the following DNA-oligonucleotide primers (KpnI and SacI restriction endonuclease recognition/cleavage sites are underlined): RPS12_forw. GGGGTACCCTAATACAC-TTTTGATAACAAACTAAAG; RPS12_rev. CCGAGCTCCCTACCAAACATAAATGAACCTG. The PCR-amplicon was cloned into the KpnI and SacI endonuclease restriction sites of phagemid $\mathrm{pBSSKII}^{-}$(Invitrogen) and transcripts were generated by run off in vitro transcription from linearized plasmid templates using T7-RNA polymerase. RNAs were purified from nonincorporated NTPs by size exclusion chromatography followed by $\mathrm{EtOH}$ precipitation. RNA pellets were redissolved in $10 \mathrm{mM}$ Tris/ $\mathrm{HCl}$ pH 7.5, $1 \mathrm{mM}$ EDTA (TE).

2.2. UV-Melting Curves. RPS12 transcripts were dissolved in $0.5 \mathrm{x} \mathrm{TE} \mathrm{pH} 7.5(50 \mu \mathrm{L})$, heated to $95^{\circ} \mathrm{C}(2 \mathrm{~min})$, and snap-cooled on ice before the addition of a concentrated folding buffer to yield a final volume of $0.5 \mathrm{~mL}$. Final buffer concentrations were as follows: $5 \mathrm{mM}$ Na-cacodylate, $\mathrm{pH}$ 6.8, $70 \mathrm{mM} \mathrm{NaCl}$, and $\pm 2 \mathrm{mM} \mathrm{MgCl}_{2}$. Volume-occupied conditions were generated by supplementing the folding buffer with $\mathrm{PEG}_{4000}$ at a final concentration of $6 \%(\mathrm{w} / \mathrm{w})$. This exceeds the polymer crossover concentration $\left(\phi^{*}\right)$ of $\mathrm{PEG}_{4000}$ by a factor of 1.5 and thus represents a highly crowded solvent regime. RNA concentrations were adjusted to $A_{260}=0.5$. Denaturation/renaturation profiles were measured at $260 \mathrm{~nm}$ between $20^{\circ} \mathrm{C}$ and $95^{\circ} \mathrm{C}$ at a heating/cooling rate of $1^{\circ} \mathrm{C} / \mathrm{min}$ (data acquisition: 0.3 data points $/{ }^{\circ} \mathrm{C}$ ). Melting temperatures $\left(T_{m}\right)$ were obtained from the maximum of the first derivatives $\left(\delta A_{260} / \delta T\right)$ of the melting curves.

2.3. SHAPE Modification. The modification reagent 1methyl-7-nitroisatoic anhydride (1M7) was synthesized as described [26]. RPS12 pre-mRNA $(0.1 \mu \mathrm{M})$ was denatured by heating to $95^{\circ} \mathrm{C}(2 \mathrm{~min})$ followed by snap cooling on ice. RNA refolding was achieved by equilibration in $20 \mathrm{mM}$ HEPES, $\mathrm{pH} 7.5,30 \mathrm{mM} \mathrm{KCl}$, and $\pm 10 \mathrm{mM} \mathrm{MgCl}_{2}$ for $30 \mathrm{~min}$ at $27^{\circ} \mathrm{C}$, which represents the optimal growth temperature of insect-stage trypanosomes. Crowding conditions were induced by either $6 \%(\mathrm{w} / \mathrm{w}) \mathrm{PEG}_{4000}\left(1.5 \phi^{*}\right) ; 12 \%(\mathrm{w} / \mathrm{w})$ $\mathrm{PEG}_{4000}\left(3 \phi^{*}\right)$; or $9 \%(\mathrm{w} / \mathrm{w}) \mathrm{PEG}_{2000}\left(1.5 \phi^{*}\right)$. RNA samples were split and treated either with $3.5 \mathrm{mM} 1 \mathrm{M} 7$ in DMSO or the same volume of neat DMSO. Modification reactions were quenched after $70 \mathrm{sec}$ by the addition of an equal volume of water. RNAs were recovered by EtOH precipitation and desalted by size exclusion chromatography. The different crowding conditions resulted in nearly identical modification results (see Figure S1 in Supplementary Material available online at https://doi.org/10.1155/2017/6067345) with Pearson's $(r)$ and Spearman's $(\rho)$ correlation coefficients $\geq 0.87$ and an average standard deviation of \pm 0.11 SU (SHAPE units).

\subsection{Reverse Transcription and Data Processing. Equimo-} lar amounts of fluorescently labelled DNA-oligonucleotide primer T3 reverse, 6-FAM/JOE/TAMRA-AATTAACCCTCACTAAA-GGGAAC, were annealed to $1 \mathrm{M} 7$-modified or 1 M7-unmodified RNA samples in $0.25 x$ TE pH 7.5 by heating to $95^{\circ} \mathrm{C}(2 \mathrm{~min})$, cooling to $50^{\circ} \mathrm{C}(10 \mathrm{~min})$, and snap cooling on ice. Reverse transcription was performed in $50 \mathrm{mM}$ Tris/ $\mathrm{HCl}$ pH 8.3, $75 \mathrm{mM} \mathrm{NaCl}, 3 \mathrm{mM} \mathrm{MgCl} 2,2.5 \mathrm{mM}$ DTT, $0.25 \mathrm{mM}$ each dNTP, and $0.75 \mathrm{U} / \mu \mathrm{L}$ RiboLock RNase inhibitor (Invitrogen). The reaction was started by prewarming the samples for 1.5 min prior to the addition of $5 \mathrm{U} / \mu \mathrm{L}$ SuperScript III reverse transcriptase (Invitrogen). RPS12 pre-mRNA was reverse-transcribed for $20 \mathrm{~min}$ at $40^{\circ} \mathrm{C}$. Sequencing reactions were carried out using unmodified RNA, fluorescently labelled DNA-oligonucleotide primer, and ddCTP or ddGTP at a final concentration of $0.125 \mathrm{mM}$ each. Reverse transcription was stopped by snap cooling and the addition of 0.1 volume of $4 \mathrm{M} \mathrm{NaOH}$ followed by heating to $95^{\circ} \mathrm{C}$ ( $\left.5 \mathrm{~min}\right)$. Samples were pooled, EtOH precipitated, and redissolved in $\mathrm{Hi}-\mathrm{Di}^{\circledR}$ formamide (ABI/Life technologies) for capillary electrophoresis. Raw electrophoretic traces were analyzed using SHAPEfinder [27] utilizing the box plot approach to determine the number of statistical outliers. Normalized SHAPE reactivities were the result of averaging a minimum of 3 independent experiments.

2.5. SHAPE-Directed RNA Folding. Normalized SHAPE reactivities were used as pseudo-Gibbs free energy $(\Delta G)$ values to guide the folding of the RPS12 pre-mRNA. The minimum free energy (MFE) 2D structure of the RPS12 transcript was generated using the ShapeKnots routine (see [28]) included in RNA structure 5.6 (see [29]) utilizing the default parameters $m=1.8 \mathrm{kcal} / \mathrm{mol} ; b=0.6 \mathrm{kcal} / \mathrm{mol}$ and $p 1=0.35 \mathrm{kcal} / \mathrm{mol}$; $p 2=0.65 \mathrm{kcal} / \mathrm{mol}$. Structure comparisons were performed using CircleCompare [29]. MFE structures were compared in terms of their "sensitivity" (sens) and their positive predictive values (ppv): sens = fraction of bp in the reference structure also present in the nonreference structure; $\mathrm{ppv}=$ fraction of bp in the nonreference structure also occurring in the reference structure. RPS12 pre-mRNA probed in dilute buffer at physiological that is $10 \mathrm{mM} \mathrm{Mg}^{2+}$-ion concentrations served as a reference state if not indicated otherwise.

\section{Results and Discussion}

To study the impact of macromolecular crowding on the structure of mitochondrial pre-mRNAs in Trypanosoma brucei, we used the primary transcript of RPS12 as a representative model RNA. The pre-mRNA molecule is $325 \mathrm{nt}$ long. 
As a pan-edited transcript, it is edited throughout its entire primary sequence with $132 \mathrm{U}$-nt inserted and $28 \mathrm{U}$ 's deleted. The RNA has a G-nt-content of $27 \%$ and a purine/pyrimidine $(R / Y)$ ratio of 1.3. Its experimentally determined minimum free energy (MFE) 2D structure calculates to a Gibbs free energy $(\Delta G)$ of $-152 \mathrm{kcal} / \mathrm{mol}$ with a base-paired versus single-stranded nucleotide ratio $\left(r_{\mathrm{bp} / \mathrm{ss}}\right)$ of 0.62 . In addition, the RNA contains a pseudoknot [22]. Since in cell structure probing experiments have successfully been performed only with abundant, cytosolic RNAs (see [5, 30-33]), we decided to mimic the crowded, intramitochondrial solvent environment by using a chemically inert, synthetic cosolute such as polyethylene glycol (PEG) $[34,35]$. We used two different high molecular mass PEGs with mean molecular

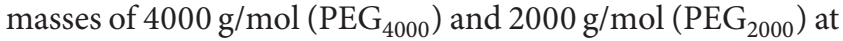
concentrations above the polymer crossover concentrations $\left(\phi^{*}\right)$, which marks the transition from a semidilute to a crowded solvent regime [36-38] (for details, see Materials and Methods).

As a first comparison, we measured UV-melting profiles of the RPS12 pre-mRNA in dilute and crowded solvent conditions. Representative normalized melting profiles and their 1st derivatives $\left(\delta A_{260} / \delta T\right)$ are shown in Figure 1(a). At dilute buffer conditions (in the presence of $70 \mathrm{mM} \mathrm{Na}^{+}$ and $2 \mathrm{mM} \mathrm{Mg}^{2+}$ ), the pre-mRNA displays a complex melting profile with 5 distinct helix/coil transitions: Two dominant transitions with melting midpoints $\left(T_{m}\right.$-values) at $46^{\circ} \mathrm{C}$ and $78^{\circ} \mathrm{C}$ and three minor transitions at $30^{\circ} \mathrm{C}, 53^{\circ} \mathrm{C}$, and $62^{\circ} \mathrm{C}$. Almost identical traces were recorded at crowded solvent conditions (Figure 1(a)). As demonstrated in the difference melting-curve in Figure 1(b), the two profiles superimpose perfectly at temperatures $\leq 40^{\circ} \mathrm{C}$ and deviate only slightly above $40^{\circ} \mathrm{C}$. At that temperature, the "crowded" profile shifts to higher temperature values, however only marginally with $\Delta T$ of maximally $4^{\circ} \mathrm{C}$ (Figure $1(\mathrm{c})$ ). This indicates a very small structural stabilization of the transcript at volume-occupied solvent conditions. Since $\mathrm{Mg}^{2+}$-cations are known to drive the structural stabilization of RNAs, we wondered whether any larger impact of the crowding agent was masked by the presence of $\mathrm{Mg}^{2+}$-cations. As a consequence, we reanalyzed the melting profile of RPS12-RNA in the absence of $\mathrm{Mg}^{2+}$. Representative normalized UV-melting curves and their 1st derivatives $\left(\delta A_{260} / \delta T\right)$ are shown in Figure 1(a). As expected, at dilute solvent conditions, the melting profiles changed drastically: $T_{m}$ of the main transition shifted by $9.5^{\circ} \mathrm{C}$ from $44.1^{\circ} \mathrm{C}$ to $34.6^{\circ} \mathrm{C}$ and the formerly high temperature transition at $78^{\circ} \mathrm{C}$ disappeared altogether. However, as before, the PEGinduced stabilization was very small with $\Delta T_{m}$ of $3.4^{\circ} \mathrm{C}$ for the main transition (Figure 1(a) and Table 1(a)). This demonstrates that the crowding-driven stabilization of RPS12 RNA is by far weaker than the stabilization by divalent cations and that the impact on the overall structure of the transcript is minute.

As a follow-up of these experiments, we analyzed the effects of macromolecular crowding by probing the structure of the RPS12 RNA with nucleotide resolution. For that we used selective $2^{\prime}$-hydroxyl acylation analyzed by primer extension (SHAPE) [39]. SHAPE monitors the local nucleotide flexibility of conformationally unrestrained nucleotides.

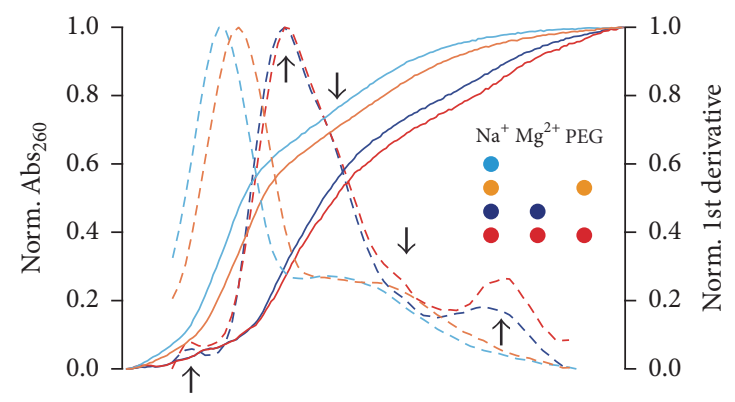

(a)

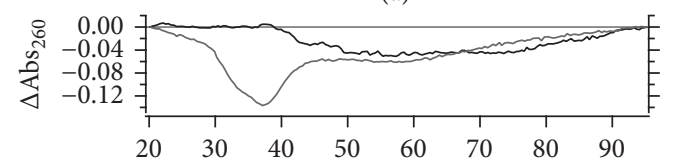

(b)

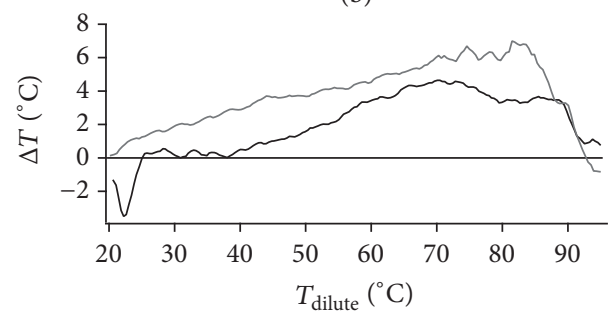

(c)

FIgURE 1: (a) Normalized thermal UV-denaturation profiles of the RPS12 pre-mRNA from Trypanosoma brucei (colored, solid lines) at different buffered solvent conditions. Red/orange: crowded solvent conditions $\left(6 \%(\mathrm{w} / \mathrm{w}) \mathrm{PEG}_{4000}\right)$. Blue/cyan: dilute solvent

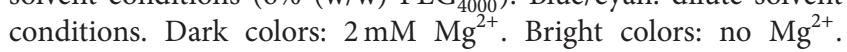
Dashed traces: normalized 1st derivatives $\left(\delta A_{260} / \delta T\right)$ of the different melting profiles. Five helix-coil transitions are marked with arrows. (b) Difference $(\Delta)$ UV-melting profiles (dilute minus crowded conditions) in the presence/absence of $\mathrm{Mg}^{2+}$-cations (black/grey). (c) Shifting of the UV-denaturation profiles to higher temperatures expressed as $\Delta T$ versus $T$ of the dilute condition in presence/absence of $\mathrm{Mg}^{2+}$-cations (black/grey).

In toto 282 nucleotides were interrogated using the four different solvent regimes depicted in Figure 2. The nucleotide flexibility is measured in normalized SHAPE units (SU) and, as expected, the RPS12 transcript displays a complex reactivity pattern including highly reactive $(>0.8 \mathrm{SU})$ and almost unresponsive $(<0.35 \mathrm{SU})$ sequence regions in dilute solvent conditions [22]. Sequence stretches with moderate $(0.35 \leq \mathrm{SU} \leq 0.8)$ to high flexibility are mostly clustered and alternate with unreactive sequence stretches (Figure 2(a)). About half of the nucleotide positions are inflexible and roughly $10 \%$ are highly flexible $(>0.8 \mathrm{SU})$. The same probing experiments were performed at crowded conditions and the SHAPE-reactivity differences in the two solvent regimes were plotted as a difference $\left(\Delta_{\text {crowded-dilute }}\right)$ SHAPE profile (Figure 2(b), top panel). The two data sets are characterized by Pearson's $(r)$ and Spearman's $(\rho)$ correlation coefficients $\geq$ 0.92 (Tables S1C/D) indicating that the structure of the RPS12 RNA is nearly identical in the two solvent regimes.

As expected, a comparison of the SHAPE profiles in the absence of $\mathrm{Mg}^{2+}$-ions resulted in a different picture. In the 

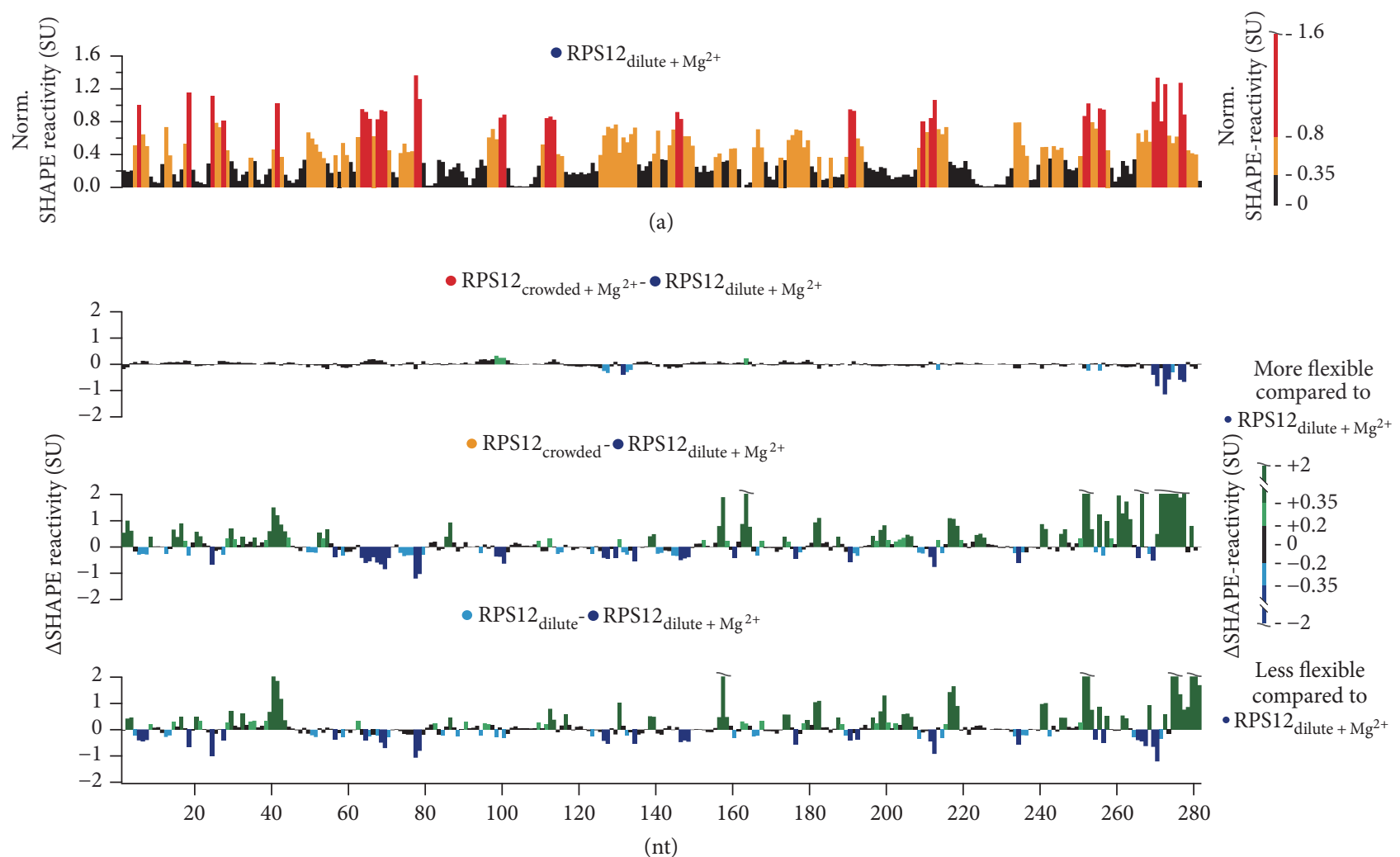

(b)

FIGURE 2: (a) Normalized SHAPE-reactivity profile of the RPS12 pre-mRNA in dilute solvent conditions. Black: low ( $<0.35$ SU); orange: medium $(0.35 \leq \mathrm{SU}<0.8)$; red: high $(\geq 0.8)$ normalized SHAPE reactivities. SU: SHAPE-unit. nt: nucleotide(s). (b) Difference $(\Delta)$ SHAPEreactivity profiles of the RPS12 transcript at crowded and/or $\mathrm{Mg}^{2+}$-free solvent conditions. Green: nt-positions with increased SHAPE reactivities (dark green: $0.35 \leq \mathrm{SU} \leq 2$; light green: $0.2 \leq \mathrm{SU}<0.35$ ). Blue: nt-positions with decreased SHAPE reactivities (light blue: $-0.2 \geq$ $\mathrm{SU}>-0.35$; dark blue: $-0.35 \leq \mathrm{SU} \leq-0.2)$. Black: nonresponsive nt-positions $(-0.2 \leq \mathrm{SU} \geq 0.2)$.

TABLE 1: (a) Helix/coil transition temperatures $\left(T_{m}\right)$ of the T. brucei RPS12 pre-mRNA derived from the denaturation profiles shown in Figure 1. Macromolecular crowding was mimicked by $6 \%(\mathrm{w} / \mathrm{w}) \mathrm{PEG}_{4000}$. (b) Summary of SHAPE-derived Gibbs free energies $(\Delta G)$ and structural characteristics of the RPS12 transcript in dilute and crowded solvent conditions. In addition, mean and median SHAPE reactivities are provided. (c) Structural features of the RPS12 pre-mRNA in crowded and/or $\mathrm{Mg}^{2+}$-free solvent conditions compared to dilute solvent conditions at $2 \mathrm{mM} \mathrm{Mg}^{2+} . \Delta \Delta G$ : difference Gibbs free energies; sens: sensitivity; ppv: positive predictive value. For a comprehensive comparison, see Table S1.

(a)

\begin{tabular}{lcccc}
\hline & Dilute $+\mathrm{Mg}^{2+}$ & Crowded $+\mathrm{Mg}^{2+}$ & Dilute & Crowded \\
\hline$T_{m}\left({ }^{\circ} \mathrm{C}\right)_{\text {main transition }}$ & 44.1 & 44.6 & 34.6 & 37.1 \\
\hline
\end{tabular}

(b)

\begin{tabular}{lcccc}
\hline & Dilute $+\mathrm{Mg}^{2+}$ & Crowded $+\mathrm{Mg}^{2+}$ & Dilute & Crowded \\
\hline$\Delta G_{37^{\circ} \mathrm{C}}(\mathrm{kcal} / \mathrm{mol})$ & -127.4 & -131.3 & -91.1 & -91.8 \\
Fraction ss & 0.38 & 0.38 & 0.43 & 0.46 \\
Fraction ds & 0.62 & 0.62 & 0.57 & 0.54 \\
Mean reactivity & 0.45 & 0.39 & 0.57 & 0.61 \\
Median reactivity & 0.35 & 0.32 & 0.35 & 0.37 \\
Pseudoknotted & yes & yes & no & no \\
\hline
\end{tabular}

(c)

\begin{tabular}{lccc}
\hline & Crowded $+\mathrm{Mg}^{2+}$ versus dilute $+\mathrm{Mg}^{2+}$ & Dilute versus dilute $+\mathrm{Mg}^{2+}$ & Crowded versus dilute $+\mathrm{Mg}^{2+}$ \\
\hline$\Delta T_{m}\left({ }^{\circ} \mathrm{C}\right)$ & 0.5 & -9.5 & -7.0 \\
$\Delta \Delta G_{37^{\circ} \mathrm{C}}(\mathrm{kcal} / \mathrm{mol})$ & -3.9 & 36.3 & 35.6 \\
sens $(\%)$ & 100 & 56 & 52 \\
$\operatorname{ppv}(\%)$ & 100 & 60 & 58 \\
\hline
\end{tabular}



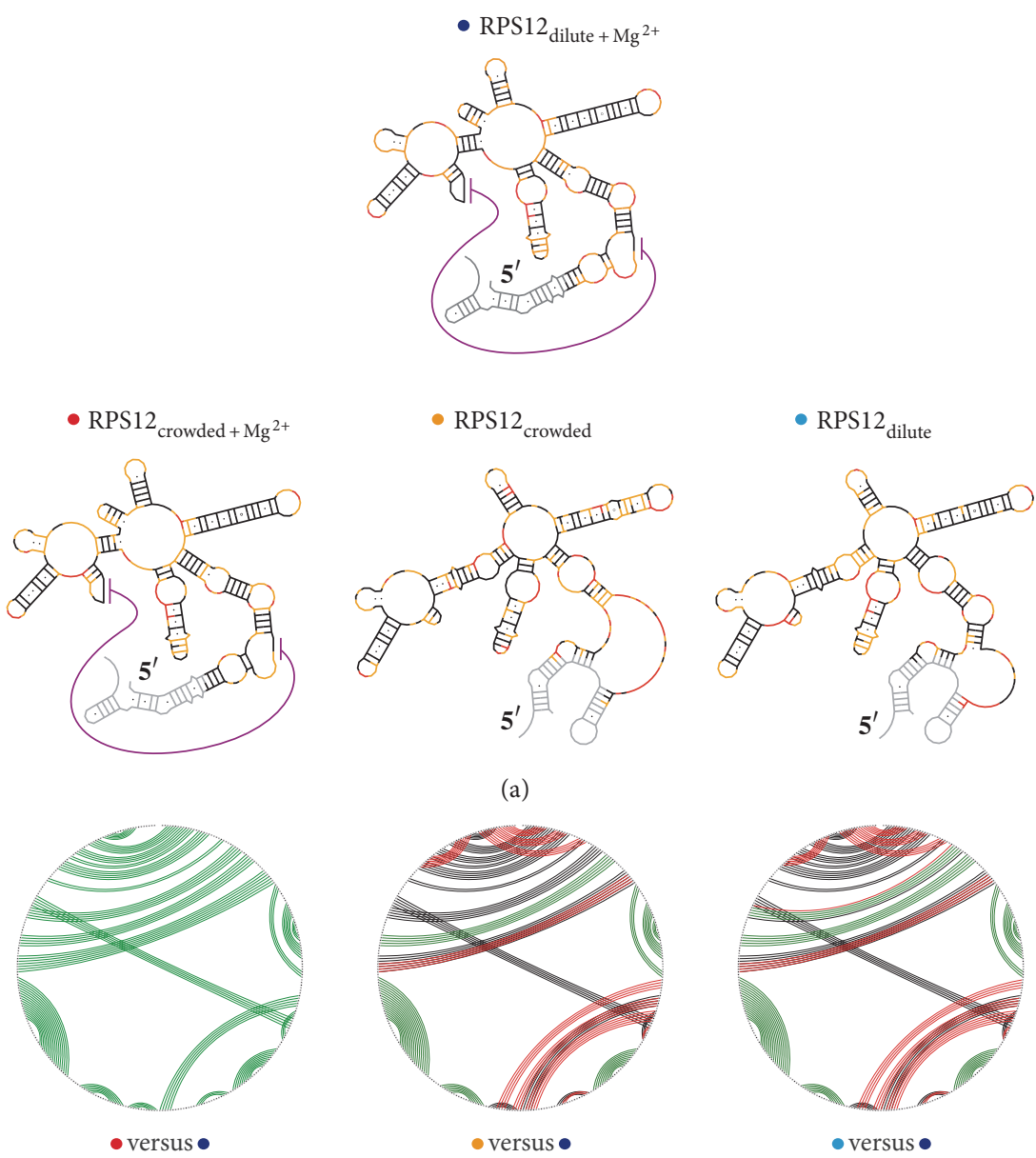

(a)
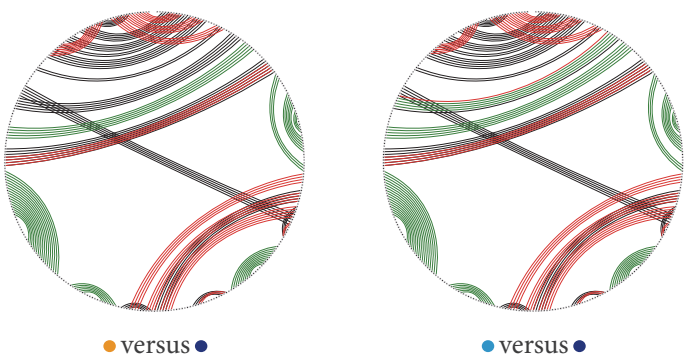

(b)

FIGURE 3: (a) SHAPE-derived minimum free energy (MFE) 2D structures of the RPS12 pre-mRNA: top, at dilute solvent conditions in the presence of $2 \mathrm{mM} \mathrm{Mg}^{2+}$; bottom, at crowded solvent conditions in the presence/absence of $2 \mathrm{mM} \mathrm{Mg}^{2+}$. (b) Circle-plot comparison of SHAPEderived 2D structures of the RPS12 pre-mRNA. Base pairs (bp) are shown as colored lines. Green: bp present in both dilute and crowded solvent conditions. Black: bp unique to dilute solvent conditions in the presence of $\mathrm{Mg}^{2+}$. Red: bp unique to the specific solvent conditions.

absence of the divalent cation, both $\triangle$ SHAPE profiles change throughout the entire primary sequence (Figure 2(b), center and bottom panel). About $20 \%$ of the nucleotides display reactivity changes $>|0.2| \mathrm{SU}$ and an additional $33 \%$ show more than a $|0.35| \mathrm{SU}$ difference. As a result, the data sets only correlate with correlation coefficients of $r=0.27$ ( $\rho=0.35$ ) (crowded- $\mathrm{Mg}^{2+}$ versus dilute) and $r=0.4$ $(\rho=0.51)$ (dilute- $\mathrm{Mg}^{2+}$ versus dilute) (Tables S1C/D and Figure S2). This behavior translates to the 2D-structure level when the normalized SHAPE reactivities are used as pseudofree-energy constraints to guide the structure prediction. Figure 3 shows the pseudoknotted 2D structure of the RPS12 transcript in dilute and crowded solvent conditions. Molecular crowding has no effect on the transcript if $\mathrm{Mg}^{2+}$ ions are present. However, since the average and median nucleotide flexibility are slightly decreased at crowded solvent conditions, this results in a decrease of the Gibbs free energy $(\Delta G)$ of $-3.9 \mathrm{kcal} / \mathrm{mol}$ (Tables $1(\mathrm{~b})$ and $1(\mathrm{c})$ ). By contrast, in the absence of $\mathrm{Mg}^{2+}$-ions, the two structures are characterized by a roughly $15 \%$ higher $\Delta G$ and the absence of the pseudoknot. Sixty percent of the nucleotides retain their structural context at all conditions studied (Figure S3 and Table S1).

These results are in line with the published data of Soto et al., 2007, and Tyrrell et al., 2015 (see [3, 40]). As expected, $\mathrm{Mg}^{2+}$-ions exert a stabilizing effect on the global fold of RNA molecules, which is reflected in a $\Delta T_{m}$ of $15^{\circ} \mathrm{C}$ and a $\Delta \Delta G$ of $-36 \mathrm{kcal} / \mathrm{mol}$. The contributions of PEG-induced macromolecular crowding to the RNA stability were less pronounced. Crowding conditions caused an increase of the main $T_{m} \leq 2^{\circ} \mathrm{C}$ and a decrease in the Gibb's free energy of maximally $4 \mathrm{kcal} / \mathrm{mol}$. Similar trends have been described by Katari et al., 2013, and by Kilburn et al., 2013, [18, 24]. The results obtained by SHAPE- and UV-thermal melting experiments in the absence of $\mathrm{Mg}^{2+}$-ions are at a first glance contradictory. The addition of $\mathrm{PEG}_{4000}$ resulted in an increase of $T_{m}$ by about $2^{\circ} \mathrm{C}$ but had no effect on $\Delta G$. Crowding conditions on average even increased the local nucleotide flexibility and had a destabilizing effect on some formerly stable structural elements (Table 1 and Figure 3). This can 
be explained by the excluded volume effect lowering the degrees of freedom for conformational sampling ultimately trapping the RNA in misfolded states [18, 40]. Alternatively, it is possible that the main transition represents a particularly stable stem structure in the RPS12 pre-mRNA that is further stabilized by PEG. However, this local difference does not manifest itself in the SHAPE-data based, global $\Delta G$-calculation. When $\mathrm{Mg}^{2+}$ is present, charge compensation by the ion-sphere and/or chelated $\mathrm{Mg}^{2+}$-ions lead to an electrostatic collapse of the RNA, thereby generating a highly compact folding state that is further stabilized by the excluded volume effect $[3,4,17,41-45]$. In the presence and absence of $\mathrm{Mg}^{2+}$-ions, the crowding-induced stabilization of the RPS12 pre-mRNA over the entire temperature range most likely results from a perturbed folding landscape due to a reduced conformationally freedom [18]. Based on the data, we conclude that there is no difference in the $2 \mathrm{D}$ structure of RPS12 pre-mRNA in dilute and crowded solvent conditions at physiological $\mathrm{Mg}^{2+}$-ion concentrations. This is in line with a recent study of Tyrrell et al., 2015 [40]. The authors used SHAPE to compare the folding of the aptamer domain of the adenine riboswitch at dilute, crowded, and in vivo conditions in its free and ligand-bound state. They demonstrated that the $2 \mathrm{D}$ structure of the ligand-free aptamer is recapitulated correctly at all conditions despite less pronounced 3D interactions in vitro. Furthermore, ligand addition resulted in the formation of a more compact conformation involving several higher-order 3D interactions that were invariantly mapped in dilute and crowded solvent conditions and inside the cell. Based on our data, we have no evidence for a crowdinginduced destabilization of RNA 2D structure in favour of tertiary structure as reported by by Nakano et al., 2009, and Strulson et al., 2014 [46, 47]. However, while the SHAPE data rule out any $2 \mathrm{D}$-structure destabilization, we cannot exclude some effects on the 3D structure of the RNA, which cannot be detected by SHAPE (such as helix packing involving helix/helix interactions).

The RPS12 transcript displays nonvarying local nucleotide flexibilities as well as identical melting profiles at dilute and crowded conditions given that $\mathrm{Mg}^{2+}$ is present. This suggests a highly stable and compact structure that obviously is not affected by volume exclusion effects. Thus, we conclude that the in vitro experiments properly reproduce the in vivo situation, at least on the level of RNA secondary structure. Furthermore, we conclude that the described sensitivity of the trypanosomal in vitro RNA editing system [24] cannot be attributed to the structure of the preedited substrate mRNAs, which suggests that the catalytic machinery that is the editosome might be sensitive to volume exclusion conditions. Editosomes are high molecular mass (0.8 MDa), protein-only complexes and the effects of molecular crowding on proteins and protein complexes has been described in detail (reviewed in [48]).

\section{Conclusions}

Mitochondrial transcript maturation in African trypanosomes and other kinetoplastid organisms requires RNA editing in order to generate functional mRNAs. The reaction takes place within the single mitochondrion of trypanosomes, which represents the most crowded environment within eukaryotic cells. RNA substrates of the editing reaction are sequence-deficient preedited mRNAs. Next to the lack of sequence information, they are characterized by the unusual feature of adopting extraordinarily stable secondary structures in dilute solvent conditions. Here we analyzed the effect(s) of macromolecular crowding on the structure of the mitochondrial RPS12 pre-mRNA as an archetypical example of a trypanosome mitochondrial transcript. We demonstrated that macromolecular crowding has no impact on the 2D fold of the RPS12 transcript and we conclude that the minimum free energy (MFE) structure identified in dilute solvent conditions represents a good proxy for the folding of the pre-mRNA in its crowded mitochondrial solvent context. We hypothesize that the data can be extrapolated to all other mitochondrial transcripts in African trypanosomes.

\section{Disclosure}

The manuscript is part of the Ph.D. thesis of W.-Matthias Leeder (http://tuprints.ulb.tu-darmstadt.de/5591/).

\section{Conflicts of Interest}

The authors declare that they have no conflicts of interest.

\section{Acknowledgments}

This work was supported by the German Research Foundation (DFG-SFB902) and the Dr. Illing Foundation for Molecular Chemistry to HUG.

\section{References}

[1] J. A. Doudna and T. R. Cech, "The chemical repertoire of natural ribozymes," Nature, vol. 418, no. 6894, pp. 222-228, 2002.

[2] D. E. Draper, D. Grilley, and A. M. Soto, "Ions and RNA folding," Annual Review of Biophysics and Biomolecular Structure, vol. 34, pp. 221-243, 2005.

[3] A. M. Soto, V. Misra, and D. E. Draper, "Tertiary structure of an RNA pseudoknot is stabilized by 'diffuse' $\mathrm{Mg}^{2+}$ ions," Biochemistry, vol. 46, no. 11, pp. 2973-2983, 2007.

[4] D. Leipply and D. E. Draper, "Dependence of RNA tertiary structural stability on $\mathrm{Mg}^{2+}$ concentration: interpretation of the hill equation and coefficient," Biochemistry, vol. 49, no. 9, pp. 1843-1853, 2010.

[5] J. Tyrrell, J. L. McGinnis, K. M. Weeks, and G. J. Pielak, "The cellular environment stabilizes adenine riboswitch RNA structure," Biochemistry, vol. 52, no. 48, pp. 8777-8785, 2013.

[6] G. S. Manning, "The molecular theory of polyelectrolyte solutions with applications to the electrostatic properties of polynucleotides," Quarterly Reviews of Biophysics, vol. 11, no. 2, pp. 179-246, 1978.

[7] V. K. Misra and D. E. Draper, " $\mathrm{Mg}^{2+}$ binding to tRNA revisited: the nonlinear Poisson-Boltzmann model," Journal of Molecular Biology, vol. 299, no. 3, pp. 813-825, 2000.

[8] D. Lambert, D. Leipply, R. Shiman, and D. E. Draper, "The influence of monovalent cation size on the stability of RNA 
tertiary structures," Journal of Molecular Biology, vol. 390, no. 4, pp. 791-804, 2009.

[9] S. Miyamoto, K. Kashiwagi, K. Ito, S. Watanabe, and K. Igarashi, "Estimation of polyamine distribution and polyamine stimulation of protein synthesis in Escherichia coli," Archives of Biochemistry and Biophysics, vol. 300, no. 1, pp. 63-68, 1993.

[10] D. Lambert and D. E. Draper, "Effects of Osmolytes on RNA secondary and tertiary structure stabilities and RNA- $\mathrm{Mg}^{2+}$ interactions," Journal of Molecular Biology, vol. 370, no. 5, pp. 993-1005, 2007.

[11] B. D. Bennett, E. H. Kimball, M. Gao, R. Osterhout, S. J. Van Dien, and J. D. Rabinowitz, "Absolute metabolite concentrations and implied enzyme active site occupancy in Escherichia coli," Nature Chemical Biology, vol. 5, no. 8, pp. 593-599, 2009.

[12] D. Lambert, D. Leipply, and D. E. Draper, "The Osmolyte TMAO stabilizes native RNA tertiary structures in the absence of $\mathrm{Mg}^{2+}$ : evidence for a large barrier to folding from phosphate dehydration," Journal of Molecular Biology, vol. 404, no. 1, pp. 138-157, 2010.

[13] R. J. Trachman and D. E. Draper, "Comparison of interactions of diamine and $\mathrm{Mg}^{2+}$ with RNA tertiary structures: similar versus differential effects on the stabilities of diverse RNA folds," Biochemistry, vol. 52, no. 34, pp. 5911-5919, 2013.

[14] S. B. Zimmerman and S. O. Trach, "Estimation of macromolecule concentrations and excluded volume effects for the cytoplasm of Escherichia coli," Journal of Molecular Biology, vol. 222, no. 3, pp. 599-620, 1991.

[15] R. J. Ellis, "Macromolecular crowding: obvious but underappreciated," Trends in Biochemical Sciences, vol. 26, no. 10, pp. 597604, 2001.

[16] D. Thirumalai, D. K. Klimov, and G. H. Lorimer, "Caging helps proteins fold," Proceedings of the National Academy of Sciences of the United States of America, vol. 100, no. 20, pp. 11195-11197, 2003.

[17] D. Kilburn, J. H. Roh, L. Guo, R. M. Briber, and S. A. Woodson, "Molecular crowding stabilizes folded RNA structure by the excluded volume effect," Journal of the American Chemical Society, vol. 132, no. 25, pp. 8690-8696, 2010.

[18] D. Kilburn, J. H. Roh, R. Behrouzi, R. M. Briber, and S. A. Woodson, "Crowders perturb the entropy of RNA energy landscapes to favor folding," Journal of the American Chemical Society, vol. 135, no. 27, pp. 10055-10063, 2013.

[19] H. U. Göringer, "'Gestalt', composition and function of the Trypanosoma brucei editosome," Annual Review of Microbiology, vol. 66, pp. 65-82, 2012.

[20] P. A. Srere, "The infrastructure of the mitochondrial matrix," Trends in Biochemical Sciences, vol. 5, no. 5, pp. 120-121, 1980.

[21] K. S. Harve, R. Lareu, R. Rajagopalan, and M. Raghunath, "Understanding how the crowded interior of cells stabilizes DNA/DNA and DNA/RNA hybrids-in silico predictions and in vitro evidence," Nucleic Acids Research, vol. 38, no. 1, pp. 172-181, 2009.

[22] W.-M. Leeder, C. Voigt, M. Brecht, and H. U. Göringer, "The RNA chaperone activity of the Trypanosoma brucei editosome raises the dynamic of bound pre-mRNAs," Scientific Reports, vol. 6, Article ID 19309, 2016.

[23] W.-M. Leeder, N. F. C. Hummel, and H. U. Göringer, "Multiple G-quartet structures in pre-edited mRNAs suggest evolutionary driving force for RNA editing in trypanosomes," Scientific Reports, vol. 6, Article ID 29810, 2016.
[24] V. S. Katari, L. Van Esdonk, and H. U. Göringer, "Molecular crowding inhibits U-insertion/deletion RNA editing in vitro: consequences for the in vivo reaction," PLOS ONE, vol. 8, no. 12, Article ID e83796, 2013.

[25] G. A. Cross, "Identification, purification and properties of clone-specific glycoprotein antigens constituting the surface coat of Trypanosoma brucei," Parasitology, vol. 71, no. 3, pp. 393417, 1975.

[26] R. Turner, K. Shefer, and M. Ares Jr., "Safer one-pot synthesis of the 'SHAPE' reagent 1-methyl-7-nitroisatoic anhydride ( $1 \mathrm{~m} 7)$," RNA, vol. 19, no. 12, pp. 1857-1863, 2013.

[27] S. M. Vasa, N. Guex, K. A. Wilkinson, K. M. Weeks, and M. C. Giddings, "ShapeFinder: a software system for high-throughput quantitative analysis of nucleic acid reactivity information resolved by capillary electrophoresis," $R N A$, vol. 14, no. 10, pp. 1979-1990, 2008.

[28] C. E. Hajdin, S. Bellaousov, W. Huggins, C. W. Leonard, D. H. Mathews, and K. M. Weeks, "Accurate SHAPE-directed RNA secondary structure modeling, including pseudoknots," Proceedings of the National Academy of Sciences of the United States of America, vol. 110, no. 14, pp. 5498-5503, 2013.

[29] J. S. Reuter and D. H. Mathews, "RNAstructure: software for RNA secondary structure prediction and analysis," $B M C$ Bioinformatics, vol. 11, article no. 129, 2010.

[30] R. C. Spitale, P. Crisalli, R. A. Flynn, E. A. Torre, E. T. Kool, and H. Y. Chang, "RNA SHAPE analysis in living cells," Nature Chemical Biology, vol. 9, no. 1, pp. 18-20, 2013.

[31] Y. Ding, Y. Tang, C. K. Kwok, Y. Zhang, P. C. Bevilacqua, and S. M. Assmann, "In vivo genome-wide profiling of RNA secondary structure reveals novel regulatory features," Nature, vol. 505, no. 7485, pp. 696-700, 2014.

[32] S. Rouskin, M. Zubradt, S. Washietl, M. Kellis, and J. S. Weissman, "Genome-wide probing of RNA structure reveals active unfolding of mRNA structures in vivo," Nature, vol. 505, no. 7485, pp. 701-705, 2014.

[33] J. L. McGinnis, Q. Liu, C. A. Lavender et al., "In-cell SHAPE reveals that free $30 \mathrm{~S}$ ribosome subunits," Proceedings of the National Academy of Sciences of the United States of America, vol. 112, no. 8, pp. 2425-2430, 2015.

[34] A. P. Minton, "The influence of macromolecular crowding and macromolecular confinement on biochemical reactions in physiological media," The Journal of Biological Chemistry, vol. 276, no. 14, pp. 10577-10580, 2001.

[35] N. A. Chebotareva, B. I. Kurganov, and N. B. Livanova, "Biochemical effects of molecular crowding," Biochemistry (Moscow), vol. 69, no. 11, pp. 1239-1251, 2004.

[36] P.-G. de Gennes, Scaling Concepts in Polymer Physics, Cornell University Press, Ithaca, NY, USA, 1979.

[37] N. Kozer and G. Schreiber, "Effect of crowding on proteinprotein association rates: fundamental differences between low and high mass crowding agents," Journal of Molecular Biology, vol. 336, no. 3, pp. 763-774, 2004.

[38] N. Kozer, Y. Y. Kuttner, G. Haran, and G. Schreiber, "Proteinprotein association in polymer solutions: from dilute to semidilute to concentrated," Biophysical Journal, vol. 92, no. 6, pp. 2139-2149, 2007.

[39] E. J. Merino, K. A. Wilkinson, J. L. Coughlan, and K. M. Weeks, "RNA structure analysis at single nucleotide resolution by Selective 2'-Hydroxyl Acylation and Primer Extension (SHAPE)," Journal of the American Chemical Society, vol. 127, no. 12, pp. 4223-4231, 2005. 
[40] J. Tyrrell, K. M. Weeks, and G. J. Pielak, "Challenge of mimicking the influences of the cellular environment on RNA structure by PEG-induced macromolecular crowding," Biochemistry, vol. 54, no. 42, pp. 6447-6453, 2015.

[41] S. L. Heilman-Miller, J. Pan, D. Thirumalai, and S. A. Woodson, "Role of counterion condensation in folding of the Tetrahymena ribozyme II. Counterion-dependence of folding kinetics," Journal of Molecular Biology, vol. 309, no. 1, pp. 57-68, 2001.

[42] S. L. Heilman-Miller, D. Thirumalai, and S. A. Woodson, "Role of counterion condensation in folding of the Tetrahymena ribozyme. I. Equilibrium stabilization by cations," Journal of Molecular Biology, vol. 306, no. 5, pp. 1157-1166, 2001.

[43] D. Thirumalai, N. Lee, S. A. Woodson, and D. K. Klimov, "Early events in RNA folding," Annual Review of Physical Chemistry, vol. 52, pp. 751-762, 2001.

[44] D. Grilley, A. M. Soto, and D. E. Draper, " $\mathrm{Mg}^{2+}-\mathrm{RNA}$ interaction free energies and their relationship to the folding of RNA tertiary structures," Proceedings of the National Academy of Sciences of the United States of America, vol. 103, no. 38, pp. 14003-14008, 2006.

[45] D. Leipply and D. E. Draper, "Evidence for a thermodynamically distinct $\mathrm{Mg}^{2+}$ ion associated with formation of an RNA tertiary structure," Journal of the American Chemical Society, vol. 133, no. 34, pp. 13397-13405, 2011.

[46] S.-I. Nakano, H. T. Karimata, Y. Kitagawa, and N. Sugimoto, "Facilitation of RNA enzyme activity in the molecular crowding media of cosolutes," Journal of the American Chemical Society, vol. 131, no. 46, pp. 16881-16888, 2009.

[47] C. A. Strulson, J. A. Boyer, E. E. Whitman, and P. C. Bevilacqua, "Molecular crowders and cosolutes promote folding cooperativity of RNA under physiological ionic conditions," RNA, vol. 20, no. 3, pp. 331-347, 2014.

[48] H. Zhou, G. Rivas, and A. P. Minton, "Macromolecular crowding and confinement: biochemical, biophysical, and potential physiological consequences," Annual Review of Biophysics, vol. 37, pp. 375-397, 2008. 

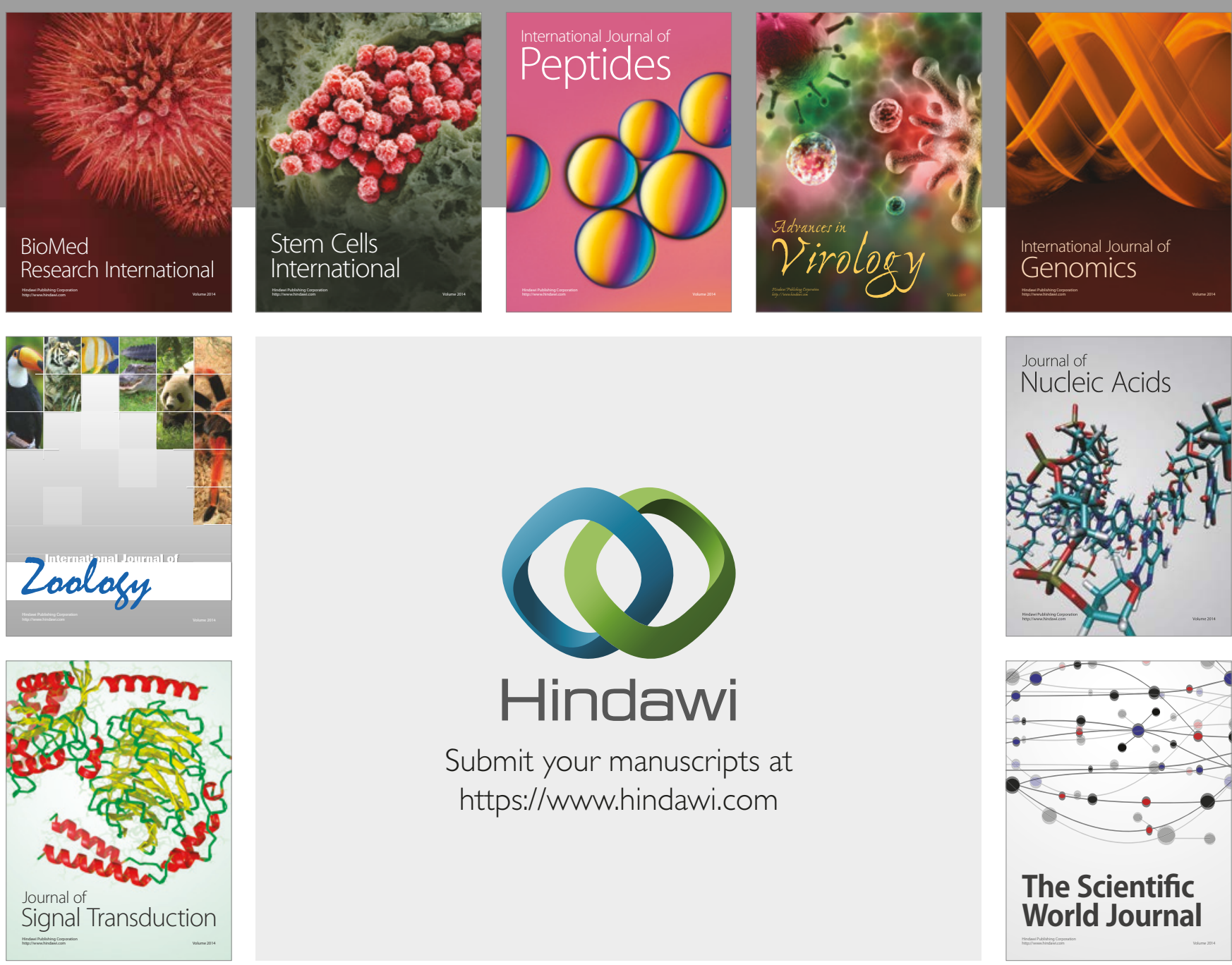

Submit your manuscripts at

https://www.hindawi.com
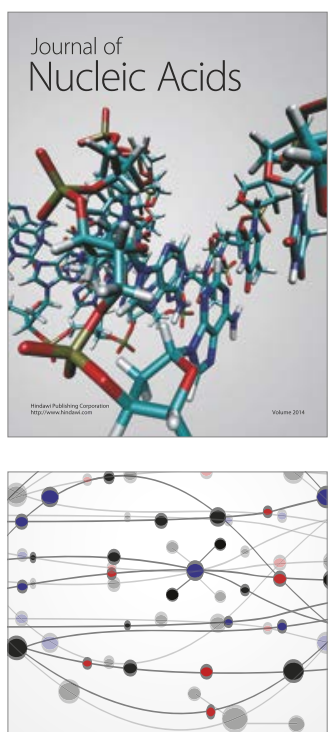

The Scientific World Journal

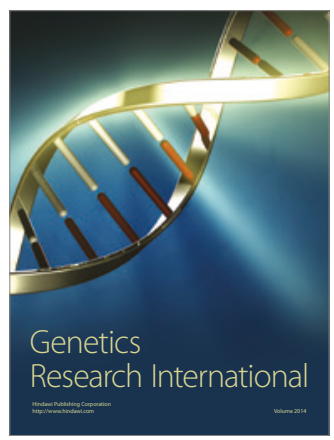

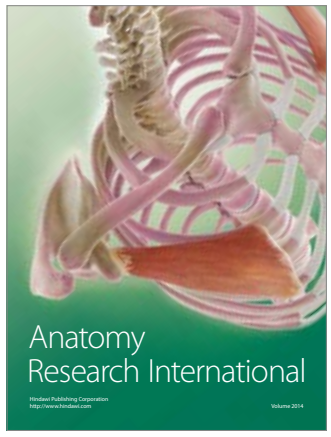

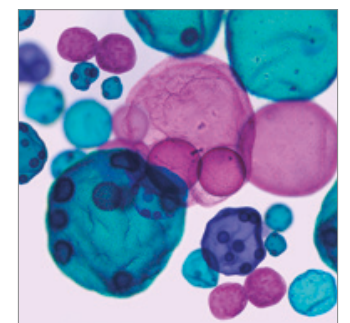

International Journal of Microbiology
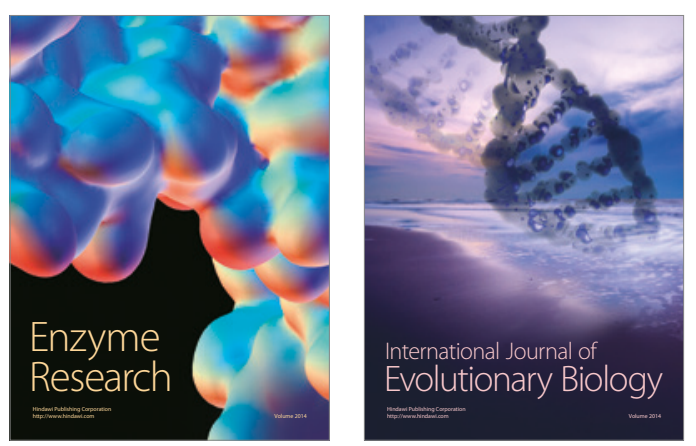
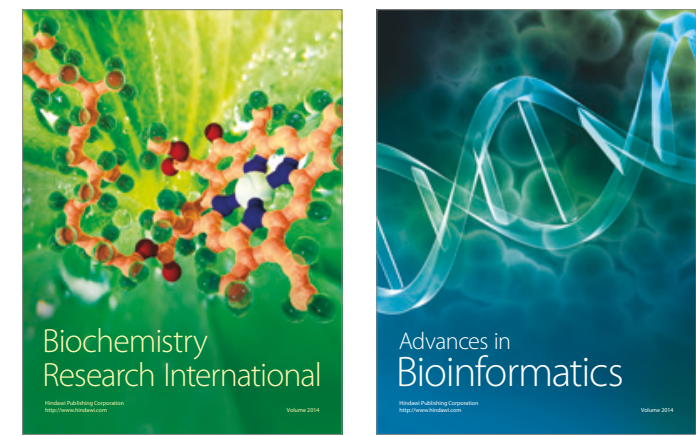

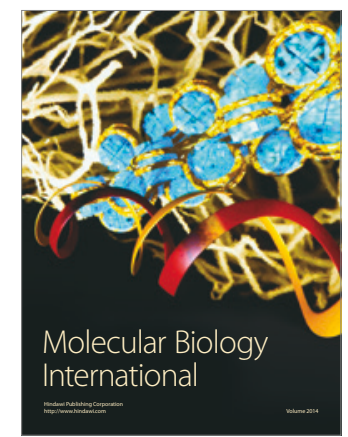

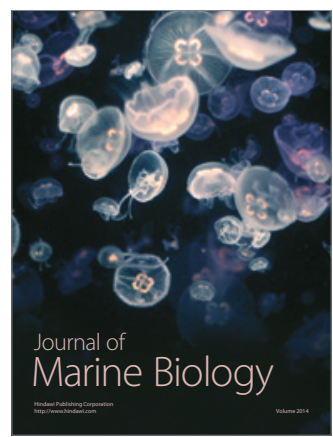

